\title{
The Effectiveness of Core Stability Exercises on Increasing Core Muscle Strength for Junior Swimming Athletes
}

\author{
Ika Novitaria Marani, Ari subarkah, Vian Octrialin \\ Faculty of Sport Science, Universitas Negeri Jakarta, Jakarta, 13220, Jakarta Timur, Indonesia
}

Received September 22, 2020; Revised November 26, 2020; Accepted December 22, 2020

\section{Cite This Paper in the following Citation Styles}

(a): [1] Ika Novitaria Marani, Ari subarkah, Vian Octrialin, "The Effectiveness of Core Stability Exercises on Increasing Core Muscle Strength for Junior Swimming Athletes," International Journal of Human Movement and Sports Sciences, Vol. 8, No. 6A, pp. 22-28, 2020. DOI: 10.13189/saj.2020.080704.

(b): Ika Novitaria Marani, Ari subarkah, Vian Octrialin (2020). The Effectiveness of Core Stability Exercises on Increasing Core Muscle Strength for Junior Swimming Athletes. International Journal of Human Movement and Sports Sciences, 8(6A), 22-28. DOI: 10.13189/saj.2020.080704.

Copyright $\mathrm{C} 2020$ by authors, all rights reserved. Authors agree that this article remains permanently open access under the terms of the Creative Commons Attribution License 4.0 International License

\begin{abstract}
Swimming is a way to maintain a streamlined body position, which requires core muscle strength; the core muscles must be strong to carry out their function in maintaining body position during swimming. Core muscle strength correlates with swimmers' buoyancy and performance. Thus, training such as core stability exercises is needed to increase the strength of the core muscles. Therefore, this study aims to determine the effectiveness of core stability exercises using a Swiss ball to increase core muscle strength in junior swimmers. An experimental method was employed with one group only pretest and posttest design. The research instrument utilized to measure the core muscle strength of junior swimmers was the sit-up test. 50 members of the Taksaka Swimming Club were determined as the population of the study while only 30 of them were involved as the sample of this study. Out of the 30 people, 15 of them were given treatment and the rest 15 people were grouped in the control group. They were divided using a purposive sampling technique. The results showed that core stability exercise using a Swiss ball was effective in increasing core muscle strength in junior swimmers as indicated by a t-score of 7.5 at the significance level of $\alpha=0.05$. Therefore, it can be concluded that core stability exercises using a Swiss ball can be used to increase the strength of the core muscles to enable the stability around the lumbar spine and abdominal muscles might bring about biomechanical changes that allow swimmers to swim faster
\end{abstract}

in a more efficient way.

Keywords Core Stability Exercises, Swiss Ball, Core Muscle Strength, Junior Swimmers

\section{Introduction}

Swimming performance benchmarks are seen from one's ability to cover a certain distance in the water in the shortest possible time. Improving swimming performance depends on the propulsion generated and minimizing resistance to movement in the water. The speed variation in each stroke cycle in swimming is caused by variations in the arm, leg, and body movements that might move the swimmer forward [1], [2]. Hence, to improve swimming performance, it is necessary to increase technique (stroke, coordination, starts, and turns techniques), biomechanical standards, the good physical condition of swimmers (flexibility, strength, aerobic, and anaerobic conditioning), and body composition of swimmers [3].

To improve the efficiency of swimmer performance and maintain the body position, streamlined and hydrodynamic need to be considered. Moreover, maintaining this posture depends on the strength of the core muscles [4]. The reason is that swimming does not have a foundation that can be used for the body to move 
forward and adjust the center of gravity to maintain the body. Thus, a swimmer is required to have a strong core muscle strength to be able to carry out the function of maintaining balance and efficient movement in water [5]. Studies have also proven that there is a strong positive correlation between core muscle strength, buoyancy, and swimming performance since the strength of the core muscles of a swimming athlete acts as a foundation to produce movement and power which leads to increased performance [6] [7].

Having strong core muscle strength enables a swimmer to perform body movements more efficiently and quickly, as it can better distribute the strength of the developing core muscles throughout the upper and lower body [8]. Panjabi [9] defined core stability as "the capacity of the stabilizing system to maintain the intervertebral neutral zones within physiological limits". The extremities connected to the spine are responsible for propelling the body into the water in swimming. Thus, having strong core muscle strength will allow more energy to be transferred to attract and maintain the one-round component of the stroke [10] [11]. Therefore, efficiency in swimming requires the involvement of the contractile qualities of the core muscles and the upper body, whereas the lower body participates little as the driving force in swimming [12].

To maximize the efficient function of motion, an important component, core stability, is needed. Core stability is the ability of the muscles around the lumbopelvic region, the center of the body during static and dynamic positions that has a function to control postural stability [13]. Therefore, to produce the desired optimal performance in sports both at speed and time, the function that must often be generated is the kinetic chain, the activation of body segments in the distal segment coordinated and sequential. The core muscles which include the spine, hips and pelvis, lower limb, and proximal are very important to give local strength and balance to reduce back injuries [8]. The core muscle is the center of almost all kinetic chains in sports activities. Hence, if it can control the strength of the core muscles, balance will be able to maximize all the kinetics chain of upper and lower body functions [14].

It is recommended for a competitive person as well as junior swimmers to do ground training to improve performance [15]. It is necessary to do exercises to train the core muscles as an integral part of a physical conditioning program to achieve greater force production in the upper and lower extremities. The core exercises program includes processes that target muscle strengthening and motor control of the core muscles to sustain movements in the same direction [16] [17]. An exercise that might be used to increase core muscle strength is core stabilization exercises, exercises that involve various muscle systems that give lumbopelvic stability to stabilize the kinetic chain. Core stability exercises are shaped by body posture, the intensity of loading, and the direction of movement [18]. Core stability allows the individual to remain balanced. It also allows a simultaneous increase in arm and leg strength. [19]. Moreover, the greater the stability of the core, the more power is expended on the arms and legs in sports performance. This is a dynamic concept that is constantly changing to suit posture or meets external loads. The presence of a strong and stable lumbopelvic region plays a role in the transfer of energy needed to create in both the upper and lower extremities [20].

Herrington L, Davies $\mathrm{R}$ said that core stability exercises are exercises that involve activation of the multifidus, transversus abdominis, and pelvic floor muscles that stabilize the lumbar region [21]. Core stability exercises in a static and dynamic environment as well as lumbopelvic stability can increase the strength of the large and small muscle groups, increase the control and balance of the body, and reduce the risk of injury [22]. Many training tools can be used to improve movement performance in a variety of conditions such as sudden changes in body direction that might lead to instability. The use of an unstable tool for core muscles is to be more active to maintain movement technique [23].

The use of an unstable tool causes the muscle groups to participate in the movement at different rates. An unstable tool that might be used in core stability exercises is the Swiss ball. A motor control system is needed in core stability exercises using a Swiss ball to stabilize the muscles around the spine [24]. Core stability exercises using the Swiss ball require a good balance to maintain the same posture on the softball, making it possible to relax or tighten the lumbar muscles from low back pain and to increase the range of motion of the spinal joints [25]. Although several studies have been conducted to look at the effects of core stability exercises on various athletic measures, not all studies have proven it to be effective. Moreover, very few studies have been conducted on swimmers relate to core stability and most of the studies include isolated strength training. Thus, this study focuses on investigating the effectiveness of core stability exercises using a Swiss ball to increase core muscle strength of junior swimmers.

\section{Materials and Methods}

\section{Research Design and Subjects}

This study employed a quasi-experimental design in the form of a nonequivalent control group design for the researchers cannot fully control external variables in the experiment. In this design, the subjects were randomly divided into two groups with different treatments. The design chart is illustrated as follows. 
Table 1. Quasi-Experimental Research Design

\begin{tabular}{clll}
\hline Research Design & $\mathrm{R}$ & $\mathrm{X}$ & $\mathrm{O}$ \\
Control group & $\mathrm{R}$ & $\mathrm{C}$ & $\mathrm{O}$ \\
\hline
\end{tabular}

The population of this study was 50 athletes of the TAKSAKA Bekasi Swimming Club. Then, 30 people were chosen as the sample of this study using a purposive sampling technique with the criteria of athletes with an age range of 10-13 years old who have mastered 4 swimming styles. Out of the 30 people, 16 were boys and 14 were girls.

\section{Research Procedure}

This study was conducted from January to March 2020. The study was carried out in 3 steps. First, a pretest was conducted to measure core muscle strength in all samples. Second, after having the pretest of core muscle strength and getting the result of swimming performance, the sample group was divided into 2 groups (experimental group and control group) randomly. After that, the initial test (pretest) and the final test (posttest) were carried out in both groups. The treatment that was only given to the experimental group consisted of 10 forms of core stability exercise using a Swiss ball. The treatment was adjusted to the characteristics of the swimming sport and the form of core stability exercise using a Swiss ball given differs each time.

The treatment was given for 16 meetings or 6 weeks with 16 meetings for the treatment frequency of three times per week. The increased intensity was given after every 3 times exercise. The intensity and duration of the core exercise given during 6 weeks treatment was continued to be increased. In the first week, the participants were performed 3 sets of 15 repetitions of each exercise. The second week, the training continued consisting of 3 sets of 20 repetitions. The third and fourth week, the training continued consisted of 4 sets of 20 repetitions of each exercise. And for the fifth and sixth week, the training continued consisted of 4 sets of 25 repetitions of each exercise.

Third, a posttest was conducted to measure core muscle strength in both experimental and control groups. The instrument used to measure core muscle strength at the pretest and posttest was the sit-up test for 1 minutes and for swimming performances, used proceeds time record of $50 \mathrm{~m}$ butterfly,

\section{Data Analysis}

The obtained data were analyzed using SPSS Statistics 25.0 for Windows. Thus, \pm SD was calculated for each group, both the experimental group and the control group, from the results of the pretest and posttest. The results were obtained from the pretest results (before the treatment for 16 meetings ( \pm 6 weeks)) and were then compared with the posttest results. Analysis of the difference in the basic group between the experimental group and the control group was carried out using the unpaired t-test and using the paired t-test whether core muscle strength in swimming athletes. Statistical significance at $p \leq .05$ has been set for post-hoc research Bonferroni's correction was used for multiple comparisons. All data provided in this analysis are presented as Mean $\pm \mathrm{SD}$.

\section{Result and Discussion}

\section{Result}

After the research data were obtained, the data then were presented in the form of data description which included the highest score, lowest score, mean, standard deviation, median, mode, frequency distribution, and histogram of the pretest and posttest results of each group (experimental group and control group). The data description from each group is presented in Table 1.

Table 2. Data Description of Pretest and Posttest from the Experimental Group and Control Group

\begin{tabular}{ccccc}
\hline Description & $\begin{array}{c}\text { Pretest } \\
\text { Experimental } \\
\text { Group }\end{array}$ & $\begin{array}{c}\text { Posttest } \\
\text { Experimental } \\
\text { Group }\end{array}$ & $\begin{array}{c}\text { Pretest } \\
\text { Control } \\
\text { Group }\end{array}$ & $\begin{array}{c}\text { Posttest } \\
\text { Control } \\
\text { Group }\end{array}$ \\
\hline $\begin{array}{c}\text { Mean } \\
\text { Standard } \\
\text { Error }\end{array}$ & 27.93 & 43.46 & 27.64 & 34.71 \\
Median & 1.00 & 1.40 & 0.76 & 0.79 \\
Mode & 28.5 & 42 & 28 & 35 \\
Standard & 25 & 40 & 25 & 33 \\
Deviation & 3.75 & 5.04 & 2.84 & 2.95 \\
Range & 13 & 17 & 9 & 9 \\
Minimum & 21 & 38 & 23 & 30 \\
Maximum & 34 & 55 & 32 & 39 \\
Sum & 391 & 565 & 387 & 486 \\
\hline
\end{tabular}

Table 2 shows the comparison between the before and after the 6 weeks treatment in the form of core stability exercises in the experimental group. There were significant differences in the experimental group with the following results: $\mathrm{t}=36.24 ; \mathrm{p}=0.00$ ). It shows an increase in core muscle strength after core stability exercises using a swiss ball was conducted for 6 weeks in the experimental group.

Table 3. Comparison between the Results of Pretest and Posttest in the Experimental Group

\begin{tabular}{ccccc}
\hline Test & Mean & SD & t-value & p \\
\hline Pre & 27.93 & 17.26 & 36.24 & $0.00($ HS) \\
Post & 43.46 & 41.8 & & \\
\hline
\end{tabular}

Table 3 presents the comparison between the control group before and after given ground exercises for six weeks. There were significant differences in the core group with the following results: $t=18.41 ; p=0.00$ ). This 
indicates an increase in core muscle strength after doing ground exercises for six weeks in the control group.

Table 4. Comparison between the Results of Pretest and Posttest in the Control Group $(\mathrm{N}=15)$.

\begin{tabular}{ccccc}
\hline Test & Mean & SD & t-value & p \\
\hline Pre & 27.64 & 10.46 & 9.62 & $0.00(\mathrm{HS})$ \\
Post & 34.71 & 12 & & \\
\hline
\end{tabular}

Table 4 shows the comparison between the experimental group $(43.9 \pm 41.8)$ and the control group $(34.71 \pm 12)$ after six weeks of core stability exercise programs using the Swiss ball and floor respectively. The results indicate that $\mathrm{t}$-value $=9.62$ with $\mathrm{p}<0$. Thus, the core stability exercises using a Swiss ball is deemed to be effective in increasing core muscle strength.

Table 5. Comparison between the Results of the Experimental Group and Control Group $(\mathrm{N}=15)$

\begin{tabular}{ccccc}
\hline Group & Mean & SD & t-value & p \\
\hline Experimental & 43.9 & 41.8 & & \\
Control & 34.2 & 12 & 9.62 & 0.00 (HS) \\
\hline
\end{tabular}

The following graph 1 showing the comparison between the pretest and posttest mean scores of the experimental group and the control group that clearly shows an increase in core muscle strength in both groups.

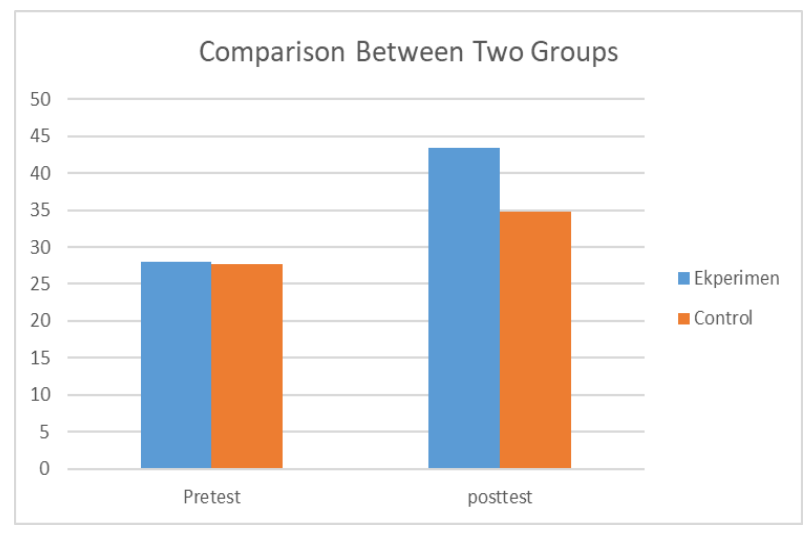

Graph 1. Comparison between mean values of pre and post-test scores of the experimental and control group

Table 6. Data Description of Pretest and Posttest from the Experimental Group and Control Group

\begin{tabular}{ccccc}
\hline \multirow{2}{*}{ Description } & \multicolumn{2}{c}{ Experiment } & \multicolumn{2}{c}{ Control } \\
& Pretest & Post test & Pretest & Post test \\
\hline Minimum & 38.56 & 36.92 & 39.56 & 36.98 \\
Maximum & 54.53 & 52.41 & 58.54 & 58.03 \\
Median & 45.54 & 42.39 & 46.42 & 47.06 \\
Modus & 45.31 & 0 & 49.36 & 0 \\
Average & 45.76 & 42.88 & 47.11 & 46.73 \\
Standard deviation & 4.72 & 4.50 & 5.61 & 5.95 \\
\hline
\end{tabular}

Here is a description of data from a record time of 50 meters butterfly style of pretest and posttest experimental group and the control group.

\section{Discussion}

This study investigated whether core stability exercises using a Swiss ball is effective in increasing core muscle strength in junior swimmers. The results show that the hypothesis proposed that core stability exercises using a Swiss ball is effective in increasing core muscle strength for junior swimmers is accepted. This can be seen based on the t-count value obtained by comparing the posttest of the experimental group with the control group of 7.5, greater than t-table of 2.24 with a significance level of $\rho<$ 0.05 . It means that core stability exercises can be carried out using a Swiss ball to increase the core muscle strength of junior swimmers. High level of core muscle stability during sports activities, is required by athletes especially swimming athletes [26].

Core muscle strength exercises using the Swiss ball aims to provide core muscle activation globally and locally. The global and local muscle groups are activating muscle subsystems that play a major role in stabilizing the core muscles. The global group consists of large and superficial muscles that transfer force between the thoracic cage and pelvis as well as act to increase intra-abdominal pressure (e.g. rectus abdominis, internal and external oblique abdominis, erector spinae, lateral quadratus luborum). In contrast, the local group consists of small muscles that control intersegmental movements between adjacent vertebrates such as multifidus, rotatores, interspinal, and intertransverse [27]. The tension in the core muscles is controlled by the nervous subsystem. As tension increases within these muscles, the comprehensive force also increases between the lumbar vertebrae that might strengthen the lumbar spine for increased stability [28].

Stability can change instantaneously on the condition that there is a postural adjustment or an external load on the body. The nervous subsystems are required to work simultaneously to ensure sufficient stability and also allow the desired joint motion to occur [28]. The transverse abdominis is a key muscle that works with the nervous subsystem to ensure adequate stability. Cresswell and Thorstensson [29] demonstrated that the transverse abdominis muscle functions primarily to increase intra-abdominal pressure that reduces the stress load on the lumbar spine. Other studies showed that the transverses abdominis is the first muscle to activate itself during unexpected body loading [30] and movement of the upper and lower limbs regardless of the direction of movement [31] [32].

It showed that some swimmers have difficulty in achieving a proximal to distal order of muscle activation. In fact, Gordon's findings [33] showed that the activation sequence was important for swimmers and can help to improve swimmers' performance. Therefore, it was necessary to do exercises to increase the sequence of activation to strengthen the core muscles. One of the exercises to train core muscle strength is by using a Swiss 
ball for studies that show that core muscle activity is higher during exercises using a Swiss ball compared to during exercises on a stable surface [34] [35]. Behm and partner [36] argue that exercises prescribed to strengthen or increase the endurance of core stabilizers for activities of daily life, sports performance, or rehabilitation should involve a destabilizing component. This study also proves that lack of stability can result from the base or platform on which the exercise is performed (in this case, it is the Swiss ball) or by placing the limb or resistance beyond the base of the body support (unilateral dumbbell holding motion). According to Charles etc. [37], the stability ball can increases hip motion and may alter muscular recruitment pattern during semi-recument exercise with little impact on cardiorespiratory.

The results of 6 weeks of core stability exercises using a Swiss ball showed a significant improvement in the strength of core muscles such as lower back and abs. Core stability exercises using a Swiss ball emphasizes the core muscles, namely the trunk extensors (lower back), flexors (stomach), lower limb extensors (quadriceps), and flexor muscle strength (hamstring), as well as abdomen, lower back, and lower leg endurance [38] [39] [40] where these core muscles are indispensable in swimming.

Science swimmers' performance is influenced by their ability to be able to generate thrust and drag experienced by swimmers while swimming, drag depends on various factors such as physical characteristics of swimmers in water [41]. Therefore, swimming training is focused on actions that might increase swimming speed and reduce movement resistance. Thus, a strong core muscle is needed to ensure strong kicks and hand pulls as well as to improve swimmers' performance. Besides, having strong core muscles can keep swimmers in a streamlined position during swimming [42]. This is what differs swimming from other sports. The core muscle is a reference for all movements in all swimming styles to improve swimmer performance.

Based on the above discussion, it can be said that it is important to have sufficient strength and stability for the body to function optimally both in the daily environment and in sports. Sports performance can be improved by training the core muscles with dynamic movements and with additional endurance by having sufficient strength and stability [43]. Moreover, one of the exercises that can be used to increase core muscle strength is to use a Swiss ball. Core stability exercises using a Swiss ball can be said to be an effective training device to increase core muscle strength as well as to improve spinal stability and flexibility [44] [45]. Thus, the significant results in this study indicate that the core stability exercises using the Swiss ball is recommended as a training method to improve the core muscle strength training of junior swimmers. For future study, a study of core stability training is possible to be carried out by comparing the involvement of the isometric and isokinetic muscles.
Furthermore, the use of appropriate tools for each of these muscle types can also be further studied.

\section{Conclusions}

Core muscles are important for stabilization and strength building in all sports activities. Judging from the efficient biomechanical function, core stability is considered important in maximizing force generation and minimizing joint loads in all types of sports activities as well as in swimming. One of the core stability exercises using a Swiss ball is considered suitable for training local and global muscle strength. The results showed that core stability exercises using a Swiss ball were effective in increasing the strength of the core muscles. Future research is expected to examine core stability exercises using other tools such as TRX to improve balance both dynamically and statically as well as its effect on swimming performance at various swimming numbers and distances.

\section{Acknowledgments}

The researchers would like to thank the swimmers for their voluntary participation and their enthusiasm for the given training program. The researchers warmly thank the TAKSAKA swimming club and coaches for their inspiring atmosphere, their interest in applied research, and for making this study possible.

\section{REFERENCES}

[1] Barbosa TM, Keskinen KL, Fernandes R, et al. Energy cost and intracyclic variation of the velocity of the centre of mass in butterfly stroke. Eur J Appl Physiol 2005; 93: 519-523.

[2] Lätt E, Jürimäe J, Haljaste K, et al. Physical development and swimming performance during biological maturation in young female swimmers. Coll Antropol 2009; 33: 117-122.

[3] De Mello Vitor F, Böhme MTS. Performance of young male swimmers in the 100-meters front crawl. Pediatr Exerc Sci 2010; 22: 278-287.

[4] Salo Dave RSA. Training for Core Stability. In Complete Conditioning for Swimminghttps://www.researchgate.net/pr ofile/Dnyanesh_Patil/publication/269108164_The_Effect_o f_Core_Strengthening_on_Performance_of_Ȳ oung_Compe titive_Swimmers/links/56af902008ae9f0ff7b26620.pdf (2008).

[5] Patil D, Salian SC, Yardi S. The Effect of Core Strengthening on Performance of Young Competitive Swimmers. Int J Sci Res 2014; 3: 2470-2477.

[6] Geladas ND, Nassis GP, Pavlicevic S. Somatic and physical 
traits affecting sprint swimming performance in young swimmers. Int J Sports Med 2005; 26: 139-144.

[7] Tomoko Okada, Kelllie C. Hildkel ATWN. Relationship Between Core Stability, FunctionaL Movement, Aand Performance. 2011; 252-261.

[8] Kibler W Ben, Press J, Sciascia A. The role of core stability in athletic function. Sports Med 2006; 36: 189-198.

[9] Panjabi MM. The stabilizing system of the spine: Part I. function, dysfunction, adaptation, and enhancement. $J$ Spinal Disord 1992; 5: 383-389.

[10] Fig G. Strength training for swimmers: Training the core. Strength Cond J 2005; 27: 40-42.

[11] Faigenbaum AD, Myer GD. Resistance training among young athletes: Safety, efficacy and injury prevention effects. Br J Sports Med 2010; 44: 56-63.

[12] Swaine IL. Arm and leg power output in swimmers during simulated swimming. Med Sci Sports Exerc 2000; 32: 12881292.

[13] Kamaz M, Kireşi D, Oğuz H, et al. CT measurement of trunk muscle areas in patients with chronic low back pain. Diagnostic Interv Radiol 2007; 13: 144-148.

[14] Arendt EA. Core strengthening. Instr Course Lect 2007; 56: 379-384.

[15] Girold S, Chadi Jalab, Olivier Bernard, Pierre Carette, Gilles Kemoun ABD. Dry-Land Strength Training Vs Electrical Stimulation in Sprint Swimming Performance. 2012; 26: 497-505.

[16] Nadler SF, Malanga GA, Bartoli LA, et al. Hip muscle imbalance and low back pain in athletes: Influence of core strengthening. Med Sci Sports Exerc 2002; 34: 9-16.

[17] Gribble PA, Hertel J. Considerations for Normalizing Measures of the Star Excursion Balance Test. Meas Phys Educ Exerc Sci 2009; 37-41.

[18] Gamble P. An integrated approach to training core stability. Strength and Conditioning Journal 2007; 29: 58-68.

[19] Keogh J. Able bodies balance training. Australas J Ageing 2009; 28: 165-165.

[20] Justin Shinkle, Thomas W. Nesser, Timothy J. Demchak and DMM. Effect of Core Strength On The Measure of Power in The Extremities. Strength Cond 2010; 26: 373380.

[21] Herrington L, Davies R. The influence of Pilates training on the ability to contract the Transversus Abdominis muscle in asymptomatic individuals. J Bodyw Mov Ther 2005; 9: 5257.

[22] Paul Comfort, Stephen J. Pearson and DM. An Electromyographical Comparison of Trunk Muscle Activity During Isometric Trunk and Dynamic Strengthening Exercises. 2011; 25: 149-154.

[23] Imai A, Kaneoka K, Okubo Y, et al. Trunk muscle activity during lumbar stabilization exercises on both a stable and unstable surface. J Orthop Sports Phys Ther 2010; 40: 369375 .
[24] Vera-Garcia FJ, Grenier SG, McGill SM. Abdominal muscle response during curl-ups on both stable and labile surfaces. Phys Ther 2000; 80: 564-569.

[25] Marshall PW, Murphy BA. Core stability exercises on and off a Swiss ball. Arch Phys Med Rehabil 2005; 86: 242-249.

[26] Sharrock C, Cropper J, Mostad J, et al. A pilot study of core stability and athletic performance: is there a relationship? Int J Sports Phys Ther 2011; 6: 63-74.

[27] McGill SM, Grenier S, Kavcic N, et al. Coordination of muscle activity to assure stability of the lumbar spine. $J$ Electromyogr Kinesiol 2003; 13: 353-359.

[28] McGill SM. Low back stability: From formal description to issues for performance and rehabilitation. Exerc Sport Sci Rev 2001; 29: 26-31.

[29] Cresswell AG, Thorstensson A. Changes in intra-abdominal pressure, trunk muscle activation and force during isokinetic lifting and lowering. Eur J Appl Physiol Occup Physiol 1994; 68: 315-321.

[30] Cresswell AG, Oddsson L, Thorstensson A. The influence of sudden perturbations on trunk muscle activity and intra-abdominal pressure while standing. Exp Brain Res 1994; 98: 336-341.

[31] Iida Y, Kanehisa H, Inaba Y, et al. Role of the coordinated activities of trunk and lower limb muscles during the landing-to-jump movement. Eur J Appl Physiol 2012; 112: $2223-2232$.

[32] McGregor AH, Hukins DWL. Lower limb involvement in spinal function and low back pain. J Back Musculoskelet Rehabil 2009; 22: 219-222.

[33] E. Barkwell G, P. Dickey J. The Effects of Plyometric Warm-up on Lower Limb Muscle Activity and Time to $10 \mathrm{~m}$ in the Backstroke Swimming Start. International Journal of Human Movement and Sports Sciences, 2018; 6: 55-62.

[34] Granacher U, Schellbach J, Klein K, et al. Effects of core strength training using stable versus unstable surfaces on physical fitness in adolescents: A randomized controlled trial. BMC Sports Sci Med Rehabil 2014; 6: 1-11.

[35] Berm KGAADG. Maintenance of EMG Activity and Loss of Force Output With Instability. J Strength Cond Res 2004; 18 : $637-640$.

[36] Behm DG, Leonard AM, Young WB, et al. Trunk muscle electromyographic activity with unstable and unilateral exercises. J Strength Cond Res 2005; 19: 193-201.

[37] R.C. Marks C, Grapsas S, Malushi D. Impact of Stability Ball Sitting during Semi-recumbent Exercise. International Journal of Human Movement and Sports Sciences, 2018; 6: $30-37$.

[38] Lehman GJ. Resistance training for performance and injury prevention in golf. J Can Chiropr Assoc 2006; 50: 27-42.

[39] Santana JC. The serape effect: A kinesiological model for core training. Strength Cond J 2003; 25: 73-74.

[40] Escamilla RF, Lewis C, Bell D, et al. Core muscle activation during Swiss ball and traditional abdominal exercises. $J$ Orthop Sports Phys Ther 2010; 40: 265-276. 
[41] Cecil Colwin-Breakthrough swimming-Human Kinetics (2002).

[42] Basu S, Chhabra S, Baxi G, et al. Effect of Core Stability Exercises on Freestyle Swimmer' s Performance Received : 5 June Revised: 13 June Accepted: 22 June Index in Cosmos International journal of basic and applied research Received: 5 June Revised: 13 June Accepted: 22 June Index. 2018; 8: 409-420.

[43] Hibbs AE, Thompson KG, French D, et al. Optimizing performance by improving core stability and core strength. Sport Med 2008; 38: 995-1008.

[44] Fredericson M, Moore T. Muscular balance, core stability, and injury prevention for middle- and long-distance runners. Phys Med Rehabil Clin N Am 2005; 16: 669-689.

[45] Gluck GS, Bendo JA, Spivak JM. The lumbar spine and low back pain in golf: a literature review of swing biomechanics and injury prevention. Spine J 2008; 8: 778-788. 